\title{
Mobbing experienced by nurses in health care facilities
}

\section{E. Zacharová, I. Bartošovič}

Original Articles

St. Elizabeth University of Health and Social Work in Bratislava, Slovak Republic

\section{Correspondence to:}

St. Elizabeth University of Health and Social Work, Department of Social Work in Skalica, Nám. slobody 3, P. O. Box 104, 810 00, Bratislava, Slovak Republic; eva.zacharova@seznam.cz

Submitted: 8.4.2016

Revised: 13.7.2016

Accepted: 4.8 .2016

\section{Reviewers:}

V. Kozon

Vienna General Hospital - Medical University Campus, Vienna, Austria

Urbanus M. Ndolo

Catholic university of Eastern Africa, Nairobi, Kenya

\section{Key words:}

Mobbing. Health care facilities. Stress. Nurse. Conflict.

CSWHI 2016; 7(2): 50-61 ๔ 2016 Clinical Social Work and Health Intervention

\section{Abstract:}

The article deals with the issues of mobbing in health care facilities. Nurse is one of the professions excessively exposed to the mobbing behaviour. Compared to other sectors, the risk of occurrence of this negative phenomenon in health care sector is up to seven times higher. The empirical part of the paper includes an analysis and a comparison of the results of the research carried out as a descriptive study with the aim to determine the extent to which mobbing is experienced by nurses, its emotional and physiological effects on the respondents and the steps taken by the individual persons to escape from the mobbing. It focuses also on the possible links between the nurses' personal traits and their vulnerability to mobbing. In order to get the necessary data, a quantitative method - through a questionnaire survey - has been used. The creation of the questionnaire has drawn inspiration from the research carried out by Nursing Administration Department, Florence Nightingale School of Nursing, Istanbul University in 2005, the respondents being nurses working in health care facilities in Turkey [1]. In order to determine the personal characteristics, the $\mathrm{M}$. Hřebíčková and T. Urbánek's NEO Five-Factor Inventory has been applied, based on the NEO Five-Factor Inventory developed by P. T. 
Costa and R. R. McCrae. The inventory identifies the levels of individual differences. It determinates the level of neuroticism, extraversion, openness to experience, agreeableness and conscientiousness. In order to obtain the statistical analysis of the data received, parametric tests have been used, i.e. the student's two-tailed t-test with the equal dispersion and Pearson correlation. The data have been processed by the STATISTICA version $10 \mathrm{CZ}$ programme. All the data have also been verified by the non-parametric tests. The research results point out problems that might occur in the health care facilities, drawing the attention of the facilities' management to emerging problems concerning the staff. It is necessary to define clear rules and procedures in order to prevent the negative behaviour practices from developing among the health care staff and to help establishing well-being in the workplace.

\section{Introduction}

The term of mobbing is derived from the English word ,to mob" = to bully, to offend, to attack or to assail somebody. Professional literature offers various definitions of the term, examples being the following: „Mobbing is a range of negative communicative behaviour of one or more individuals targeted towards a person for a longer period (for six months minimum and at least once a week).“ [2: p. 15]; ,Mobbing is a systematic, intentional and above all repetitive attack towards a person, using degradating approach, excessive criticism, mocking, minor or more serious attacks. It might also very well use a material influence." [3: p. 13]; „Mobbing is a kind of psychic torment in the workplace where very hostile and unethical forms of communication are used, as well as the attacks on a person's, ,integrity [4: p. 14]; ,The term of mobbing can be used only when it regards a systematic, recurring and long-term activity, systematic and recurring persecution and torment of a victim, where the roles of an aggressor and a victim are strictly separated and the bullying is no longer a reaction to a real or fictitious offence by a victim, but becomes a goal itself.“ [5: p. 14]; ,Mobbing - a psychic torment - is a systematic, intentional and above all repetitive attack towards a person, using degradating approach, excessive criticism, mocking, minor or more serious intrigues“ [6: p. 73]; ,Mobbing means not being integrated into a team." [4: p. 14].

A large part of his career was dedicated to this subject by Heinz Leymann (19321999), a German professor, who lived and worked in Sweden since 1955 where he specialized namely in patients suffering from communication and relation problems in the workplace. He considers mobbing to be a psychological terror in the workplace and defines it as follows: „Psychological terror or mobbing in working life involves hostile and unethical communication which is directed in a systematic manner by one or more individuals, mainly toward one individual, who, due to mobbing, is pushed into a helpless and defenceless position“" [7]. Prof. Leymann finds the time aspect to be the most important factor to distiguish between mobbing and other conflicts. To be considered as a mobbing, the actions must occur on a frequent basis (at least once a week) and over a long period of time (at least six months' duration). Because of the 
high frequency and long duration of hostile behaviour, this maltreatment results in a lot of problems, both in personal and professional life of the individual concerned. As a consequence of a social pressure, there is also mental misery such as posttraumatic stress disorder, depression, loss of concentration, mistrust, suicidal thoughts or suicide attempts, as well as psychosomatic problems such as headaches, backaches, indigestion, state of anxiety or sleep disorder. [7]. According to the International Labour Organization it is the psychological abuse that is the most serious problem in the workplace at the beginning of the new millennium.

The profession of nurse belongs to the professions which are exposed to the risk of mobbing behaviour to a significantly higher extent than other professions, the rate in the health care and social sectors being up to seven times higher. The progress of medicine knowledge and the changes in the society affect also the functions of the hospital. There are new, narrowly specialized diagnostic and therapeutic centres in hospitals, which imply the need of additional specialized training for the doctors and nurses. As a consequence, they become specialized in certain diseases. The working conditions to ensure high-quality treatment include not only spatial arrangement of the workplace, physical, chemical and biological factors which might lead to inter alia occupational disease, but also the physical and mental burden affecting the workers. While performing her occupational duties, the nurse has several roles to play: e.g. a hospital attendant, an assistant, a communicator, an instructor, an advisor, a patients' rights defender, a manager. All the professional roles are interconnected and complementary and their performance places demands not only on the nurses' professional competence but also on their personal qualities. Working in the health care sector means working in a team. Therefore, cooperation and communication with other nurses, doctors, patients and their relatives is an essential part of work. The ability to effectively evaluate a situation, choose the right words and adequately react and address a problem is a prerequisite for managing the role of a nurse. The relations between nurses and doctors are very important aspects of the overall atmosphere at work. When assessing their satisfaction at work, the nurses attribute great importance to these relations. When there is an atmosphere full of tension and conflicts, there is growing dissatisfaction, the quality of work is on the decrease, there is a frequent job changing and the nurses lose their interest in self-development. Both the doctors and nurses should be willing to mutually respect their roles and the relating responsibilities and encourage each other to meet the common goal of taking care of the patients. A well treated patient is also an objective for the work executed by the nurses. In order to meet this objective, the nurses must perform team work. That is why it is indispensable for the nurses to establish close relations at the workplace. If the team work is not respected by a nurse, the coexistence is disrupted and the efforts to meet the main objective end in failure. The same applies also to the relations between a nurse and a patient: there is a strong interdependence as regards good personal contacts. An appropriate communication may prevent a lot of conflict situations. The nurse must inspire the patient's faith in his/ her expert knowledge; he/she must show tact and patience, be aware of the patient's concerns and acknowledge his/her moods, depressions or particularities. The nurse's role requires a great deal of understanding, sympathy and kindness. Compared to other professions, the work in health care sector involves more stress. The stress factors can be non-specific (e.g. shift work, being pressed for time, role conflicts, information 
overload), as well as specific ones (being in contact with pain and death, dealing with quarrelsome patients etc.) An excessive stress increases the risk of incorrect actions and decisions, job-related injuries and psychosomatic disorders, as well as alcohol and other drugs addictions, thus worsening the state of health and work productivity of the medical staff and negatively affecting their family life. It is often difficult for nurses - as a profession assisting in somatic medicine - to meet the professional requirements as a health care specialist and at the same time provide the patients with positive energy, encourage them and listen to them. These requirements might be very exhausting for the nurses lacking an emotional balance.

\section{Defining a research problem}

This research has been carried out as a descriptive study with the aim to determine the extent to which mobbing is experienced by nurses, its emotional and physiological effects on the respondents and the steps taken by the individual persons to escape from the mobbing. Another subject of the research is the relation between personal traits and the vulnerability to mobbing.

\section{General objective}

To determine the occurrence of the mobbing experienced by nurses and the relation between mobbing and personal traits.

\section{Specific objectives}

1. To determine the occurrence of the mobbing experienced by nurses and the most frequent types of behaviour showing signs of mobbing.

2. To identify the most frequently reported physiological and emotional reactions of the nurses facing mobbing.
3. To determine the most frequent ways of dealing with the mobbing incidents experienced by nurses.

4. To find out if there is a link between the number of years of employment in nursing and the extent of the reported mobbing.

5. To find out if there is a link between the age of the nurse and the extent of the reported mobbing.

\section{Hypotheses}

H1: Within the monitored group of nurses there is a statistically significant positive link between the extent of the reported mobbing and the height of scores in the scale of neuroticism in the questionnaire NEO Big five.

$\mathrm{H} 2$ : Within the group of nurses there is a statistically significant positive link between the extent of the reported mobbing and the height of score of extraversion in the questionnaire NEO Big five.

\section{Research sample}

For the purposes of the research, the questionnaires were distributed among nurses in three hospitals in the following regions: Moravian-Silesian Region, Olomouc and Zlín. Out of 195 questionnaires which were distributed, 125 questionnaires returned back (64\%). After processing it was necessary to exclude 12 more questionnaires for their incompleteness. Therefore there were processed 113 questionnaires $(58 \%)$. For the purposes of this research, the sample of 113 nurses was considered $100 \%$.

\section{Methods}

To obtain the necessary data a quantitative research method through a questionnaire survey was conducted. The questionnaires were distributed personally with the 
Table 1 Absolute frequency of nurses, their average age and average length of time employed in nursing.

\begin{tabular}{|c|c|c|c|}
\hline & $\begin{array}{c}\text { Absolute } \\
\text { frequency }\end{array}$ & $\begin{array}{c}\text { Average } \\
\text { age }\end{array}$ & $\begin{array}{c}\text { Average } \\
\text { length of } \\
\text { time em- } \\
\text { ployed }\end{array}$ \\
\hline Nurses & 113 & 35.5 & 13.9 \\
\hline
\end{tabular}

reassurance of anonymity. Although the research was carried out with the consent of the managers of the individual hospitals and hospital departments, due to the sensitivity of the issue and the difficulty of collecting the data, the names of all medical facilities where the survey took place were not stated.

The creation of the first questionnaire drew the inspiration from the research carried out by Nursing Administration Department, Florence Nightingale School of Nursing, Istanbul University in 2005, the respondents being nurses working in health care facilities in Turkey [1]. This questionnaire had four sections. In the first section the participants' demographic information were requested. In part A questions about mobbing behaviours were asked. In part B there were questions focused on the physiological and emotional reactions to mobbing incidents and the questions in part $\mathrm{C}$ focused on the actions taken in order to escape from the mobbing. The research participants were asked to indicate the frequency of mobbing behaviours they had faced in the last six months. In the determination of frequency a six-choice type of scale from $0=$ have never faced, $1=$ have faced only once, 2 = have faced several times, $3=$ I face sometimes, $4=$ I frequently face, $5=$ I constantly face was used.

The second part of the survey consisted of the NEO Five-Factor Inventory by $M$. Hřebíčková and T. Urbánek based on the NEO Five-Factor Inventory developed by
P. T. Costa and R. R. McCrae. The inventory identifies the level of individual differences. It determines the level of neuroticism, extraversion, openness to experience, agreeableness and conscientiousness. In each of the sixty questions a respondent decided on a five-point scale from 0 "not described" to 4 "well described". The level of each personal trait expresses the sum of gross score. Each of the characteristics is measured by 12 items; the maximum score in each range is 48. The inventory asks about five personality dimensions. A dimension of neuroticism - emotional stability - examines a scale of adaptation or emotional instability. A dimension of extraversion - introversion examines quality and quantity of interpersonal reactions, the level of activation and a need for stimulation. A dimension of openness to experience detects active search for new experiences, tolerance to the unknown and its discovery. A dimension of agreeableness detects interpersonal orientation. A dimension of conscientiousness affects that kind of self-control which applies to the organization, motivation and perseverance to the goal-oriented behaviour.

In order to obtain the statistical analysis of the data received, parametric tests were used - the student's two-tailed t-test with the equal dispersion and Pearson correlation. The data were processed by the STATISTICA version $10 \mathrm{CZ}$ programme. All the data were also verified by the non-parametric tests.

\section{Results}

The first specific objective was to detect the rate of occurrence of mobbing among the nurses and what were the most frequent types of mobbing behaviours. Such questions were answered in part A of the questionnaire "The occurrence of unwanted (unfriendly) behaviour in the workplace (mobbing)". This part was focused on the description of unwanted 
behaviour in the workplace, which the respondents could have encountered within the last twelve month. The respondents commented on the 33 statements. Each of the statement was evaluated on the scale from 0 to 5 (have never faced - I constantly face). The average score of the examined sample of 113 nurses in the part A was 0.67. Within the monitored group of nurses there are 31 (27\%) of them who evaluated one of the 33 items in part A by score 4 (I often face) or 5 (I constantly face). The average score of these nurses in part A was 1.24 in contrast with the nurses, who did not evaluate any items in part A by score 4 or 5 and whose average score was 0.43 .

The second specific objective was the statements. The average score within the monitored group of 113 nurses in part B was 0.74 . Within this group of nurses there were 37 of them (33\%) who evaluated one of the 34 statements in part B by score 4 (I experience most of the time) or 5 (I experience all the time). The most commonly experienced reactions to mobbing behaviours were feelings of tiredness and stress, headaches and restless sleep. It can be said that physiological reactions were the most frequent reactions of the nurses to mobbing behaviours.

The third specific objective tracked possible ways of solving mobbing problems which the nurses had encountered. In part $\mathrm{C}$

Table 2 Most frequent types of mobbing behaviours within the monitored group of nurses.

\begin{tabular}{|l|c|c|}
\hline Statement & $\begin{array}{c}\text { Absolute } \\
\text { frequency N }\end{array}$ & $\begin{array}{c}\text { Relative } \\
\text { frequency \% }\end{array}$ \\
\hline Making me feel as if I and my work are being inspected. & 16 & $14 \%$ \\
\hline $\begin{array}{l}\text { Holding me alone responsible for the negative results of } \\
\text { work carried out by others. }\end{array}$ & 11 & $10 \%$ \\
\hline Having untrue things said about me. & 11 & $10 \%$ \\
\hline Blaming me for things that are not my responsibility. & 8 & $9 \%$ \\
\hline Not informing me about organized social meetings. & 8 & $7 \%$ \\
\hline $\begin{array}{l}\text { Having my decisions and recommendations criticized and } \\
\text { rejected. }\end{array}$ & 7 & $6 \%$ \\
\hline Being verbally threatened. & 7 & $6 \%$ \\
\hline Questioning my professional competency for every job I do. & & \\
\hline
\end{tabular}

detection of the most frequent physiological and emotional reactions to mobbing incidents. This was monitored in part B of the questionnaire, in which the respondents were asked to evaluate their emotional and physiological reactions to mobbing behaviours they had experienced in the last 12 months. The respondents evaluated the 34 of the questionnaire, the nurses were asked to indicate what they had done in situations they had faced the mobbing. The average score within the monitored group of 113 nurses in part $\mathrm{C}$ was 0.99 . Within this group of nurses there were 49 (43\%) of them who evaluated one of the 8 statements in part $\mathrm{C}$ by score 4 (I experience most of the time) or 
5 (I experience all the time). Out of 8 offered solutions the most frequent ones were: "I am working more carefully to avoid being criticized for my work" and "I am working harder and more organized". of time employed and the level of indicated mobbing.

The fifth specific objective was focused on the relationship between the age of each individual respondent and the level

Table 3 Most frequent reactions to mobbing within the monitored group of nurses.

\begin{tabular}{|l|c|c|}
\hline Statement & $\begin{array}{c}\text { Absolute } \\
\text { frequency N }\end{array}$ & $\begin{array}{c}\text { Relative } \\
\text { frequency } \%\end{array}$ \\
\hline My sleep regularity is disturbed. & 18 & $16 \%$ \\
\hline I have headache. & 16 & $14 \%$ \\
\hline I feel tired and stressed. & 14 & $12 \%$ \\
\hline I think I am depressed. & 13 & $11.5 \%$ \\
\hline I have stomach and intestinal problems. & 11 & $10 \%$ \\
\hline $\begin{array}{l}\text { My work life negatively affecting my life away from work } \\
\text { (my marriage and family). }\end{array}$ & 11 & $10 \%$ \\
\hline I am afraid when I go to work, I do not want to be at work. & 11 & $10 \%$ \\
\hline
\end{tabular}

Table 4 Most frequent types of solutions to mobbing situations within the monitored group of nurses

\begin{tabular}{|l|c|c|}
\hline Statement & $\begin{array}{c}\text { Absolute } \\
\text { frequency N }\end{array}$ & $\begin{array}{c}\text { Relative } \\
\text { frequency \% }\end{array}$ \\
\hline $\begin{array}{l}\text { I am working more carefully to avoid being criticized } \\
\text { for my work }\end{array}$ & 45 & $40 \%$ \\
\hline I am working harder and more organized. & 39 & $35 \%$ \\
\hline I am seriously thinking about quitting work. & 12 & $11 \%$ \\
\hline
\end{tabular}

The task of the fourth specific objective was the existence of relationship between the length of time employed and the rate of mobbing that the individual respondent showed. The resulting correlation values were compared with the tabulated value, in which the critical value for the monitored group of nurses $(\mathrm{N}=113)$ of the Pearson's correlation coefficient at a significance level of 0.05 was 0.214 . Within the monitored group of nurses was not found a statistical significant relationship between the length of indicated mobbing. The resulting correlations were compared with the tabulated value, in which the critical value for the monitored group of nurses $(\mathrm{N}=113)$ of the Pearson's correlation coefficient at a significance level of 0.05 was 0.214 . The results of the relationship between the age and mobbing were equal to the results of the relationship between the length of time employed and mobbing. Within the monitored group of nurses was not found a statistically significant relationship be- 
Table 5 Relationship between the length of time employed and the indicated level of mobbing within the monitored group of nurses, $\mathrm{N}=113$

\begin{tabular}{|l|c|c|c|}
\hline & $\mathrm{A}$ & $\mathrm{B}$ & $\mathrm{C}$ \\
\hline $\begin{array}{l}\text { The length of } \\
\text { time employed }\end{array}$ & 0.1356 & 0.1723 & 0.1855 \\
\hline & $\mathrm{p}=.353$ & $\mathrm{p}=.236$ & $\mathrm{p}=.202$ \\
\hline
\end{tabular}

tween the age and the level of indicated mobbing.

Based on the information from the study [8] that being exposed to the mobbing behaviours relates with individual personal traits such as neuroticism, that victims of mobbing at working place appear to be submissive, anxious and neurotic, lacking the social skills and self-confidence [9], that victims of bullying reach higher results on the scales of anxiety, worry and sensitivity on average [9] and that victims show symptoms of anxiety and depression even before

Table 6 Relationship between the age and the level of indicated mobbing within the monitored group of nurses, $\mathrm{N}=113$

\begin{tabular}{|l|c|c|c|}
\hline & $\mathrm{A}$ & $\mathrm{B}$ & $\mathrm{C}$ \\
\hline Age & 0.0703 & 0.145 & 0.1423 \\
\hline & $\mathrm{p}=.631$ & $\mathrm{p}=.320$ & $\mathrm{p}=.329$ \\
\hline
\end{tabular}

the beginning of mobbing [10], a hypothesis was formulated.

Hypothesis 1: Within the monitored group of nurses exists a statistically significant positive link between the level of indicated mobbing and the height of the score of neuroticism in the questionnaire NEO Big five. With the help of Pearson's correlation at the significance level $\mathrm{p}<.05000$ the following facts were found:
Table 7 Correlation between the scale of neuroticism and individual parts of the questionnaire Mobbing within the monitored group of nurses $(\mathrm{N}=113)$

\begin{tabular}{|c|c|c|c|}
\hline & $\mathrm{A}$ & $\mathrm{B}$ & $\mathrm{C}$ \\
\hline Neuroticism & 0.0331 & 0.2342 & 0.0495 \\
\hline & $\mathrm{p}=.822$ & $\mathrm{p}=.105$ & $\mathrm{p}=.735$ \\
\hline
\end{tabular}

There was not proved a statistically significant correlation of monitored parameters. The hypothesis 1 was not confirmed.

Out of conducted researches [11] results the information about lower levels of independence and extraversion of the victims of mobbing. In accordance with this idea a lot of the victims said that their problems had been supported by the lack of skills for managing conflict situations and the low level of self-confidence or shyness. On the basis of these statements a hypothesis was formulated.

Hypothesis 2: Within the monitored group of nurses there was a statistically significant positive correlation between the level of the indicated mobbing and the height range of scores in extraversion in the NEO Big Five questionnaire. With the help of the Pearson's correlation at a significance level $\mathrm{p}<.05000$ the following facts were found: There was not proved a statistically significant correlation of monitored parameters. The hypothesis 2 was not confirmed.

Table 8 Correlation between Extraversion and individual parts of the questionnaire Mobbing within the monitored group of nurses $(\mathrm{N}=113)$

\begin{tabular}{|l|c|c|c|}
\hline & $\mathrm{A}$ & $\mathrm{B}$ & $\mathrm{C}$ \\
\hline Extraversion & -0.0754 & -0.183 & -0.0763 \\
\hline & $\mathrm{p}=.606$ & $\mathrm{p}=.208$ & $\mathrm{p}=.602$ \\
\hline
\end{tabular}




\section{Discussion and verification of hypotheses}

This research has been carried out as a descriptive study with the aim to determine the extent to which mobbing is experienced by nurses, its emotional and physiological effects on the respondents and the steps taken by the individual persons to escape from the mobbing. Another subject of the research is the relation between personal traits and the vulnerability to mobbing.

The overall results as well as the analysis of particular items of nurses' teams show that among the most frequent types of mobbing behaviour belong 'making me feel as if I and my work are being inspected', 'holding me alone responsible for the negative results of work carried out by others', 'having untrue things said about me' and 'blaming me for things that are not my responsibility'. The nurses in their answers consider the personal aspect of communication as the most demanding. This fact might be influenced by one of the essential traits in nurses' job which is cooperation in the team. The nurse has often to rely on help of other nurses therefore it is necessary for them to trust each other to be able to take care of their patients effectively. It might be the reason why the nurses are more susceptible to the personal attacks.

The research, which was conducted at Istanbul University in 2005 with the purpose of determining the mobbing experienced by nurses who work in healthcare facilities in Turkey, shows similar results. It was found out that the most common mobbing behaviour experienced by the participants was determined to be 'having someone speak about me in a belittling manner in the presence of others' $(55.2 \%)$. The second most common mobbing behaviour experienced by the nurses was 'being blamed for things I am not responsible for' $(50.5 \%)$ and the third was 'having me feel like me and my work were being controlled' (50.1\%). A larger percentage of these results is caused by using the participants' answers of one (I have faced once) and above which were taken for evaluation.

In this study a more exacting criterion had been chosen and only the participants' answers of four (I frequently face) and five (I constantly face) were taken for evaluation.

The second specific objectives aims to identify the most frequently reported physiological and emotional reactions of the nurses facing mobbing. The most frequent reactions included disturbance of sleeping regularity, feeling tiredness and stress and having headaches. It can be said that physiological reactions were the most frequent reactions of the nurses to mobbing behaviours. These results stand in line with Yildirim A. and Yildirim D. (2007) who indicated as the two most common reactions also feeling tiredness and stress and having headaches. According to the Istanbul University research other frequent reactions were very similar - eating excessively or not having an appetite (in the Turkish research $53.5 \%$ ) and having gastrointestinal complaints (in the Turkish research 52.9\%). Moreover, there were quite a lot of participants reporting depression as a significant trait of their reaction to the working environment.

Among the emotional reactions there were mainly mentioned these describing participants' fears when they enter the workplace as well as their feeling that their life outside work is negatively affected by mobbing. These results also stand in line with Yildirim A. and Yildirim D. (2007). It was proved that most of people as a reaction to the stressful situations are stressed, tired and have headaches. In addition, if the people experience some wrong and injustice they often suffer from extreme sadness. That is why the reactions of the nurses 
facing to mobbing are understandable and expectable.

The third specific objective aims to determine the most frequent ways of dealing with the mobbing incidents experienced by nurses. The most common things the nurses did to escape from mobbing were 'to work more carefully to avoid criticism' and 'to work harder and more organized'. As well as previous results these findings also stand in line with Yildirim A. and Yildirim $D$. (2007). In addition, there were quite a lot of participants who seriously thought about changing workplaces. These results contradict with Yildirim A. and Yildirim D. (2007) who did not indicate this answer at all. This distinction might be caused by different opportunities for women in the labour market in the Czech Republic and in Turkey.

The fourth specific objective aims to find out if there is a link between the number of years of employment in nursing and the extent of the reported mobbing. No statistically significant relationships were found with the total years of service in the nursing profession and the extent of the reported mobbing.

The fifth specific objective aims to find out if there is a link between the age of the nurse and the extent of the reported mobbing. Again no statistically significant relationships were found with the nurses' age and the extent of the reported mobbing. Similar findings are reported by Yildirim A. and Yildirim D. (2007) who also did not prove this relationship. As can be seen, it is quite possible for the healthcare workers and nurses to face mobbing behaviours regardless to their age.

Mobbing behaviours at workplace are influenced by the combination of lots of factors in one particular moment in time. As the main factors can be considered the personality of an aggressor, the personality of a victim, working environment, quality of management, structure of the organization, overworking stress, reorganization, existential uncertainty, boredom or monotony. It is evident that mobbing behaviour is not significantly connected with one specific trait, for example with the age of nurse or the number of years of employment in nursing. Even a new member of the staff can adapt himself/herself to the working process if working environment is positive, willing to cooperate and pass along information, open to discussion and is able to solve all the problems immediately.

Hypotheses $\mathrm{H} 1$ and $\mathrm{H} 2$ dealt with a statistically significant relation between the extent to which mobbing is experienced and the total score on the scale Neuroticism and Extraversion measured by the NEO Big Five Test. Statistically significant relation between the monitored parameters was not proved in this study although lots of previous researches had been confirmed it. This relation was confirmed for example in Coyne I. and Seigne E. study which examined the extent that workplace victim status can be predicted from personality traits. Victims tended to be less independent and extroverted, less stable, and more conscientious than non-victims. Significance of mobbing at the workplace is mentioned by Niedl [1] who observed 368 employees working in Austrian public hospitals. He found out that the victims of mobbing suffered more from anxiety, depression, irritation and psychosomatic problems than people who were not exposed to mobbing behaviours. In Ireland O'Moore, Seigne, McGuire and Smith [9] found out that the victims of mobbing achieved in average lower results than the reference group at Catell's 16PF related to emotional stability and dominance as well as higher results at the scale of anxiety, fears and sensitivity. Although the findings in this study, which might be influenced by a lower number of the participants, have not confirmed similar results mentioned above, it can be said - according to results based 
on the previous research, that the victims of mobbing at the workplace show signs of submissiveness, anxiety, neuroticism, lack of social skills and self-confidence but on the other hand they are characterized by the behaviour focused on effort to succeed. The presence and frequency of mobbing behaviours faced in the facilities can be an indicator of the awareness that the most valuable presence in the facility is human resources. Present development of the society, individual's entering the labour market and a pressure on his/her career growth as well as incorrectly solved interpersonal conflicts among the co-workers might be the reason of occurrence of the attitudes and behaviours which first can cause tension at the workplace and finally lead to mobbing behaviours. In this study it was found that all nurses, regardless of their age, educational status and position, can be exposed to mobbing behaviours at the workplace. As can be seen at every workplace in the world it is very important both for the employees and for the institutions to prevent hostile behaviours at the workplace. Solving long-term unresolved interpersonal conflicts with appropriate conflict resolution strategies can help decrease the development of workplace violence. In addition, mobbing behaviours at the work place need to be defined and appropriate rules and procedures need to be specified and shared with all employees to prevent the development of these mobbing behaviours. Managers are expected to adopt an open managerial approach to prevent the development of these behaviours.

\section{Conclusion and recommendations to the clinical practice}

The purpose of the research presented in this study was to determine the occurrence of mobbing experienced by nurses, its emotional and physiological effects on the respondents and the steps taken by the indi- vidual persons to escape from the mobbing. It dealt with the research focused on the relation between personal traits and the extent to which mobbing is experienced.

The sample involved a total of 113 participants. $31(27 \%)$ of the nurses who participated in the research had faced mobbing behaviours within the last six months and they marked these behaviours on a sixpoint scale four (I frequently face) and five (I constantly face). The nurses stated attacks to personality as the most serious problem. The nurses' reactions to mobbing behaviours included feeling tired and stressed, having headaches and disturbance of sleeping regularity. The most common things the nurses did to escape from mobbing were 'to work more carefully to avoid criticism' and 'to work harder and more organized'. No statistically significant relationships were found with the nurses' age or the total years of service in the nursing profession and the extent of the reported mobbing. Moreover, no statistically significant relation was between the extent to which mobbing is experienced and the total score on the scale Neuroticism and Extraversion measured by the NEO Big Five Test.

This study pointed out a large number of problems connected with mobbing behaviours which could occur at the workplace. To prevent the development of these behaviours and avoid the negative consequences stemming from poor atmosphere at the workplace it is recommended to support communication among the employees, for example by organizing supervisor seminars. Supervision focused on the employee provides the opportunity to discuss and express personal problems connected with the work as well as to get the feedback, acknowledgment and support. Supervision also provides professional and personal development of the employees, creates a safe place for solving personal problems, encourages the 
employees to realistically reflect their own limits and possibilities, offers necessary social support and develops team interaction. These days supervision has become a very important part of work which can offer improving professional competences, support in the complicated working situations, reflection on the work, analysis of the professional topics and knowledge about the work style not only to particular employees but also to a work team or to the whole facility. These recommendations seem to be very important for nurses' teams where a higher rate of psychical and physical burdens is. These recommendations also can prevent negative forms of communication as well as support mental health all the participants.

To sum up, it must be said that mobbing is a part of daily clinical practice in health care facilities. It is recommended:

- mobbing behaviours in the work place need to be defined;

- appropriate policies and procedures need to be developed and shared with all employees to prevent the development of mobbing behaviours;

- managers should adopt an open managerial approach.

\section{References}

1. BEDNÁŘ, M., BEŇO, P.: Patology of working relations or mobbing again: Psychological bullying at work is illegal. Sondy, 2000, 11 , is. 2, p. 14.

2. COYNE, I., SEIGNE, E., RANDALL, P.: Predicting workplace victim status from personality. European Journal of Work and Organizational Psychology, 2000. 9, p. 335-349.
3. GLASO, L., MATTHIESEN, S. B., NIELSEN, M. B., EINARSEN, S.: Do targets of workplace bullying portray a general victim personality profile? Scandinavian Journal of Psychology, 2007. 48, p. 313-319.

4. JANOUŠEK, V.: Mobbing, current problem [online], January-March 2004, [cit.27.02.2011]. Available on www: $<$ http://www.zenain.cz/rubrika.asp?id$\mathrm{c}=8431 \& \mathrm{id}=2>$ a (http://www.zena-in.cz/ rubrika.asp?idc $=8603 \& i d=2$ ).

5. KRATZ, H. J.: Mobbing, how to recognize it and how to face it. Praha: Management Press, 2005, 131 s. ISBN 80-7254-953-0.

6. LEYMANN, H. 1996. [cit.27.2. 2011]. Available on: www. <http://www.leymann. se/English /frame.html>.

7. NOVÁK, T., CAPPONI V.: Alone against agressoion. Prague: Grada, 1996. 128 s. ISBN 80-7169-253-0.

8. NOVÁK, T., RICHTEROVÁ, I.: Bullying terrorizing - aggression - all these can be experienced at the workplace or mobbing in different ways. Sondy, 1999, 10, is. 22, p. 1.

9. VARTIA, M.: Consequences of workplace bullying with respect to the well-being of its targets and the observers of bullying. Scandinavian Journal of Work Environment and Health, 2001. 27, p. 63-69.

10. YILDIRIM, A., YILDIRIM, D.: Mobbing in the workplace by peers and managers: mobbing experienced by nurses working in healthcare facilities in Turkey and its effect on nurses. Journal of Clinical Nursing, 2007. 16, 8, p.1444-1453.

11. ZAPF, D.: Organisational, work group related and personal causes of mobbing/bullying at work. International Journal of Manpower. 1999. 20, p. 70-85. 